\title{
First Language Acquisition: Is It Compatible with Chaos/Complexity Theory?
}

\author{
Mohammad Hashamdar \\ Department of Translation Studies, Karaj Branch, Islamic Azad University, Karaj, Iran \\ Email: mohamad.hashamdar@kiau.ac.ir
}

\begin{abstract}
This paper intends to use analogy to describe first language acquisition. Larsen-Freeman (1997) asserted that "analogies are only helpful if by knowing something about one member of the pair, we can advance our understanding of the other" (p.157). It is difficult to tell if the analogy between chaos/complexity theory and first language acquisition can be beneficial for the researchers to have better understanding of first language acquisition. This study can be considered as unique in its own place. Few articles have been devoted to this type of analogy. Most researchers have preferred to deal with the issue of second language acquisition and chaos/complexity theory. The researcher hopes to have shed some light on the issue and expects to attract the attention of the other researcher to this analogy. The purpose of science is better understanding of the world and the phenomena inside it. Therefore, it is expected to better understand the most complex phenomenon which is nothing more than first language acquisition.
\end{abstract}

Index Terms - adaptivity, attractor, chaos/complexity theory, dynamicity, linearity, sensitive initial state

\section{INTRODUCTION}

The study of first language acquisition has a long back since it has long been the interest of scholars from different disciplines. It was late $19^{\text {th }}$ when many researchers tried to study the development of child language by keeping extensive diaries of their children's language development. At first they were all based on pure observation of this phenomenon, however, they were followed by extensive audio and visual records.

At the very beginning, many of language acquisition studies were undertaken to assess the psychological reality of a linguistic theory. However, there were some problems ahead. First, linguistic theory is a theory about product not process, so it could not predict the process of language acquisition. Second, linguistic theories displaced each other rapidly giving no time to be evaluated. Nevertheless, the need of theories from other disciplines accompanying first language acquisition is a must and cannot be eliminated. Observation should always be supported by theories to be reliable and valid.

On the other hand, Chaos/complexity theory is one of those theories which have influenced the study of second language acquisition throughout the recent years. However, it was rarely considered a theory which can be applied and compared in first language acquisition. The purpose of this paper is to draw attention to the similarities among complex nonlinear systems occurring in nature and of language and language acquisition. It should be reminded that the analogy may only be metaphoric.

The origin of chaos/complexity theory dates back to the 1960s work of meteorologist Edward Lorenz. Lorenz developed a simple meteorological model based on differential equations. When he ran his model on a computer, Lorenz discovered that a very small difference (less than one part in one thousand) in the initial conditions led to large changes in the weather predicted by his model over time. This discovery, sensitivity to initial conditions, is one of the fundamental characteristics of chaos theory. Over the past few decades, chaos theory has been used widely in the natural sciences. More recently, it has also begun to be applied to the social sciences as well as applied linguistics. Kauffman (1995) stated that complex systems are composed of agents that interact with and adapt to one another and the environment, co-evolving and self-organizing without any central control.

Complexity theory has attracted some attention in educational research. Scholars have used it as a framework to investigate teaching and learning (Barab et al., 1999; Davis \& Sumara, 1997; Davis, Sumara, \& Luce-Kapler, 2000), teacher education (Zellermayer, 2005), educational administration (Griffiths, 1997; Sullivan, 1999), curriculum (Doll, 1989, 1993), second language acquisition (Larsen-Freeman, 1997), and ecological approach to language learning (Van Lier, 2000).

In language learning, Thornbury (2001) argued that language and language learning share some features with other complex systems. It is dynamic and non-linear; adaptive and feedback sensitive; self-organizing; and emergent. He stated "the learner's grammar restructures itself as it responds to incoming data. There seems to be periods of little change alternating with periods of a great deal of flux and variability, and even some backsliding. In this way, process grammars are not unlike other complex systems which fluctuate between chaotic states and states of relative stability" (p. 48). 


\section{CHAOS/COMPLEXITY THEORY}

Chaos/complexity theory, like many other theories, has been defined differently by different scholars in the field. According to one definition, "Chaos theory is the qualitative study of unstable aperiodic behavior in deterministic nonlinear dynamical systems." This definition provided us with several conclusions about the characteristics of chaos. First, it states that the system is dynamical. It means that it changes over time. Second, that the behavior of the system is aperiodic and unstable means that it does not repeat itself. Third, although chaotic behavior is complex, it can have simple causes. Fourth, because the system is nonlinear, it is, as we have already seen, sensitive to initial conditions. (Nonlinearity means that the output of the system is not proportional to the input and that the system does not conform to the principle of additivity, i.e., it may involve synergistic reactions in which the whole is not equal to the sum of its parts). Fifth, because the system is deterministic, chaotic behavior is not random even though its aperiodicity and unpredictability may make it appear to be so. On the other hand, because of the instability, aperiodicity, and sensitivity to initial conditions, the behavior of chaotic systems is not predictable even though it is deterministic. A final feature of chaos, although not included in the above definition, is that of iteration or feedback, in which the output of the system is used as the input in the next calculation.

The above-mentioned characteristics all belonged to the chaotic system. However, as the title of the theory states, it is both chaotic and complex. A complex system is one in which numerous independent elements continuously interact and spontaneously organize and reorganize themselves into more and more elaborate structures over time. Complexity is characterized by: (a) a large number of similar but independent elements or agents; (b) persistent movement and responses by these elements to other agents; (c) adaptiveness so that the system adjusts to new situations to ensure survival; (d) self-organization, in which order in the system forms spontaneously; (e) local rules that apply to each agent; and (f) progression in complexity so that over time the system becomes larger and more sophisticated. As with chaos, the behavior of self-organizing complex systems cannot be predicted, and they do not observe the principle of additivity, i.e., their components cannot be divided up and studied in isolation. Complex systems can naturally evolve to a state of self-organized criticality, in which behavior lies at the border between order and disorder. As Gleick(1987) claimed "the study of chaos is a science of process rather than state, of becoming rather than being" (p.5).

Larsen-Freeman (1997) characterized a number of features for a chaos complex system. She stated that the system is dynamic, complex, nonlinear, chaotic, unpredictable, sensitive to initial condition, open, self-organizing, feedback sensitive, and adaptive.

Now it is time to search for the compatibility of chaos/complexity theory and the process of first language acquisition. In order to do this, each characteristic of chaos/complexity theory is discussed separately under one heading and then decision is made if it exists in the first language acquisition.

\section{ChaOs/COMPLEXITY THEORY AND FIRST LANGUAGE ACQUISITION}

The study of chaotic and complex nonlinear systems and the study of first language acquisition have much in common. In order to manifest this analogy, first and for most, the nature of language can be conceptualized as systematic, however, it is debatable that a view of language as a dynamic system can be easily recognized. LarsenFreeman (1997) elaborated on this issue and stated "the first common meaning of dynamic as applied to language is that of process-language can be described as an aggregation of static units or products, but their use in actual speech involves an active process, usually referred to as parole (Saussure) or performance (Chomsky)" (p. 147). Further, she mentioned the second common way that language is recognized dynamic is when dynamic is equated with growth and change.

Now let's study the features of chaos/complexity theory in first language acquisition.

\section{A. Dynamicity}

The study of dynamic systems is not a new in science. What makes these innovative is that their focus is complex systems. These systems are termed complex for two reasons.

A system is called dynamic when it changes over time. It stands against a stable system in which there is no change over time. Therefore, the study of dynamicity refers to the study of process rather than state, or of becoming rather than being.

Dynamicity of language can best be observed when the first language acquisition is under study. First language acquisition is the process of acquiring the first language over time with ultimate changes. It is believed that this rapid change can mainly be observed in the process of vocabulary learning in infants.

Diller (1995) stated that "the act of using the language meaningfully has a way of changing the grammar system in the user" (p.116). It emphasizes that every time language is used, it changes. As one writes or utters a sentence, she/he changes the language. This type of change is called emergentism. This view suggests that language grows and organizes itself from the bottom up in an organic way. While rules can be used to describe such systems, the systems themselves are not the product of rules. Mitchener and Nowak (2004) asserted "languages are not static. Phonological systems tend to change systematically but unpredictably" (p.701). 
Dynamicity of first language can best be observed throughout life if one wishes to learn rhetoric. Even if one is highly educated but prefers to ameliorate his ability in speech for the academic purposes, he practices his way of speech and it is hoped to have better performance. This also indicated the property of dynamicity in first language.

Langacker (2001) believed that conceptualization in the mind is inherently dynamic. He stated that it locates in mental processing, so every conception requires some span of processing time, however brief, for its occurrence. He also argued that dynamicity is essential to linguistic semantics. How a conceptualization develops and unfolds through processing time is often (if not always) a pivotal factor in the meanings of expressions.

\section{B. Nonlinearity}

In chaos/complexity theory, complex systems are nonlinear. A nonlinear system is one in which the effect is disproportionate to the cause. However, in a linear system a cause of a particular strength results in an effect of equal strength. Something which is very important is that nonlinear systems can also sometimes exhibit linearity; however, at other times, they may react in a way that is all out of proportion to the cause. The other vital issue is that complex nonlinear systems behave in a regular, orderly way until a critical point is passed, and then they go chaotic.

Larsen-Freeman (1997) stated "learning linguistic items is not a linear process_learners do not master one item and then move on to another. In fact the learning curve for a single item is not linear either" (p.151).

First language acquisition is primarily a linear process, but this linearity does not continue. As the infant utters the first word, this linearity vanishes into thin air. After all, learners do not master one item and then move on to another. The best example is when beginners acquire English language and produce the past tense of irregular and regular verbs. It is surmised that these are mastered incrementally at a lexical level. After further exposure to the target language, however, chaos happens. Regular past form -ed is over-generalized and this indicates the nonlinearity of first language acquisition.

\section{Unpredictability}

It is believed that the beginning of the randomness of complex nonlinear systems is unpredictable. There will always be uncertainty and surprise as long as human beings are involved. If you look at this unpredictability from a complex systems viewpoint, it is a positive contributor to the new experiences that can result in learning.

Kirshbaum (2002) explained that the unpredictability that is thus inherent in the natural evolution of complex systems then can yield results that are totally unpredictable based on knowledge of the original conditions. Such unpredictable results are called emergent properties. Emergent properties thus show how complex systems are inherently creative ones.

First language acquisition is unpredictable. The reasons can be due to different issues. First, the outcome of language acquisition is not measurable and predictable. Some may come up with full mastery of their mother tongue. Some might be able to have sweet language with nice, polite, attractive words, some may have bitter language with a limited number of words. Although the role of education cannot be ignored in the quality of one's mother tongue, they are many who have the same level of education but they are better lecturers. Second, the role of exposure to language by caregivers is still unknown. Researcher worked hard to find out caregivers' role in the speech of infants. They are now sure of the importance of exposure; however, they cannot surely prove that the kind of exposure would have benefit for the child's performance in future. Third, the age of language mastery is unpredictable. In linguistics book, the development of language acquisition has been isolated by the age of the infant. For example, it is claimed that when the child is around 12 to 14 months old, they could articulated about 50 words of their mother tongue. However, it has been observed that in many cases, Iranian children at these ages are not capable of producing that number of words.

\section{Sensitivity to Initial State}

The term initial conditions refers to the components of the system and how they relate to each other and the environment. The effects of their relationship will be magnified as interactions take place over time, and large divergences may appear from what were initially very small differences. In terms of first language acquisition, it is useful to think about the fact that no two days ever seem to be in the same way. In this process, the infant acquires the language day after day and the previous stage does not come back.

\section{E. Openness}

A complex chaotic system is open. It is open to new matter and energy infusion, entropy is not inevitable. As open systems evolve, they increase in order and complexity by observing energy from the environment.

In first language acquisition, the input contains a variety of forms, structures, vocabulary, and lexical items. This openness to input is not limited to first language; it continues to contain second, third, and more languages. The advantage of this property is that it helps to creativity, innovation, and diversity in language use.

Larsen-Freeman (1999) stated "Language is an open system, one that is evolving and changing. If this is true of language, it must also be true of its learning- it will never be complete if the target is always moving" (p.43). This can best be seen in mother tongues of people in the world. No one can claim she/he knows their mother tongue perfectly well, even those have technically studied their it. 
The input data triggers the creation or formation of novel complexities. These complexities might be beyond the complexities of the input. The infusion of input to previous input can produce a type of entropy. This entropy is because of regularity and irregularity of some components of language. The best example again would be the past form of English verbs. First - $e d$ form (regular) and then irregular form which cause entropy in the mind of infants acquiring the first language.

\section{F. Adaptivity}

A chaotic complex system after passing the turmoil would tend to a self organizing state. The system adjusts to new situations to ensure survival. Kauffman (1991) stated that complex systems in biology have the capacity to naturally select and self-organize and are adaptive. These systems do not simply respond passively to events; they actively try to turn whatever happens to their advantage. They are capable of learning, although learning process- testing a model against reality and then modifying it to match- occurs at different time intervals (Berreby, 1994).

In the process of first language acquisition this adaptive system can be detected and found in different strata. As the infant starts conversing, they often try to change their production to match that of their caregivers. This ability to adjust increases with experience each meaningful instance adding to their repertoire of adjusting capabilities for future partners.

Piaget considers adaptation a basic process in development and defines two aspects of adaptation: assimilation and accommodation. For the child to survive in the world, he must learn to adapt. This involves an interface between assimilation and accommodation. According to Piaget, it is only through adaptation that people interact with their environment.

Describing adaptation, Piaget contends that in every interaction, schemas are not applied without a recognition 0f the varying properties of objects and a subsequent adaptation.

A schema modifies itself according to the particular characteristics of the object; the schema of reaching for and grasping something must accommodate to the distance of the object and to its size and weight. As a result, no two applications of a schema, however simple, are exactly alike. Nevertheless, there is a basic similarity which gives the schema its organization, permitting its repetition and consequent growth.

\section{G. Complexity}

In complexity theory a system is defined as a set of interwoven components that interact in particular ways to generate some overall form at a particular point in time. As it is mentioned a system has elements that interact to shape a connected whole. However, it can be called a complex one when it is a system with different types of elements, usually in large numbers with changes all the time.

Now first we have to prove that language is complex, and then indicate the process of first language acquisition is a complex matter. Larsen-Freeman (1997) believed that language is complex. She stated "Language satisfies both criteria of complexity: first, it is composed of many different subsystems- phonology, morphology, lexicon, syntax, semantics, and pragmatics. Second, the subsystems are interdependent. A change in any one of them can result in a change in the others" (p.149). By studying different elements involved in the process of language acquisition, no one can definitely say which part is more complex than the other one. Some believe that syntax is the most complex element of language. The studies based on processing that investigates child language acquisition have shown that certain structures are intrinsically more problematic for children because of the complexity in their syntactic structure. Domínguez and Guijarro-Fuentes (2010) provided an example of the so called 'filler-gap' structures such as wh-questions. Since the wh-word (the filler) has to be held in working memory by the child until it can be properly linked to a long-distance gap, it is not unexpected that the acquisition of wh-questions are indeed a source of problems for children.

The first language acquisition is also known to be complex. There are many factors involved in the process of first language acquisition which are interdependent. Some of them are the type and amount of input, the amount and type of interaction, the amount and type of feedback received, and other factors which make first language acquisition a complex web. Consequently, these complex phenomenon causes diversity in the first language acquisition.

Birjandi and Hashamdar (2009) elaborated on the diversity of first language acquisition and studied it under the category of individual differences in first language acquisition. They classified these differences under four different dimensions (linguistic, social, cognitive, and cultural dimensions), each of which with some subcategories. The main purpose of their study was to indicate that first language acquisition is a complex phenomenon. That's why diversity and differences are seen in the child's language.

Slobin (1985) distinguished two sources of complexity for learning: conceptual and formal complexity. Conceptual complexity belongs to the complexity of the ideas being expressed in language. Formal complexity refers to the forms different concepts get. For example, the concept of plural may take different forms in different languages. In English, it takes -s ending for plural and in other languages the other forms. Although no one language appears to be easier to learn and master, there are some forms which are easier to learn than in other languages. Children growing up in that language find that aspect of language easier and therefore learn it much sooner than children of other languages the same form.

\section{CONCLUSION}


In this paper, analogy is used to describe first language acquisition. Larsen-Freeman (1997) asserted that "analogies are only helpful if by knowing something about one member of a pair, we can advance our understanding of the other" (p.157). It is difficult or let's say too early to tell if the analogy between chaos/complexity theory and first language acquisition can be beneficial for the researchers to have better understanding of first language acquisition. This study can be considered as unique in its own place. A few articles have been devoted to this type of analogy. Most researchers have preferred to deal with the issue of second language acquisition and chaos/complexity theory. The researcher hopes to have shed some light on the issue and expects to attract the attention of the other researcher to this analogy. The purpose of science is better understanding of the world and the phenomena inside it. Therefore, it is expected to better understand the most complex phenomenon which is nothing more than first language acquisition.

\section{REFERENCES}

[1] Barab, S. A. et al. (1999). Principles of self-organization: learning as participation in autocatakinetic systems. The Journal of the Learning Sciences, 8, 349-390.

[2] Berreby, D. (1994). Murray gell-mann. The new York Times Magazine, 24-27.

[3] Birjandi, P., \& Hashamdar, M. (2009). Individual differences in first language acquisition. ELT Weekly, 33, 1-4.

[4] Davis, B. \& Sumara, D. J. (1997). Cognition, complexity, and teacher education. Harvard Educational Review, 67, $105-125$.

[5] Davis, B. et al. (2000). Engaging minds: learning and teaching in a complex world. Mahwah, NJ: Lawrence Erlbaum Associates.

[6] Doll, W. E. (1989). Complexity in the classroom. Educational leadership, 47, 65-70.

[7] Doll, W. E. (1993). Curriculum possibilities in a "post"-future. Journal of Curriculum and Supervision, 8, 277-292.

[8] Doolittle, P.E. (2000) Complex constructivism: A theoretical model of complexity and cognition. Retrieved June 22, 2010 , from http://www.chre.vt.edu/fs/doolittle/research/complex1.html.

[9] Griffiths, D. (1997). The case for theoretical pluralism. Educational Management and Administration, 25, 371-380.

[10] Guijarro-Fuentes, P., \& Domínguez, L. (2010). New directions in language acquisition: romance languages in the generative perspective. Cambridge: Cambridge Scholars Publishing.

[11] Kauffman, S. (1995). At home in the universe: the search for the laws of selforganization and complexity. New York: Oxford University Press.

[12] Langacker, R. W. (2001). Dynamicity in grammar. Axiomathes, 12, 7-33.

[13] Larsen-Freeman, D. (1997). Chaos/complexity science and second language acquisition. Applied Linguistics, 18, $141-165$.

[14] Larsen-Freeman, D. (2000). Second language acquisition and applied linguistics. In W. Grabe (ed.), Applied Linguistics as an Emerging Discipline, Annual Review of Applied Linguistics, 20, 165-181.

[15] Larsen-Freeman, D., \& Long, M.H. (1991). An introduction to second language acquisition research. New York: Longman.

[16] Larsen-Freeman, D. \& Cameron, L. (2008). Complex systems and applied linguistics. Oxford: Oxford University Press.

[17] Mallows, D. (2002). Non-linearity and the observed lesson. ELT Journal, 56 (1), 3-10.

[18] Nelson, C. (2011). The complexity of language learning. International Journal of Instruction,4 (2), 93-112.

[19] Sullivan, T. J. (1999). Leading people in a chaotic world. Journal of Educational Administration, 37, 408-423.

[20] Thornbury, S. (2001). Uncovering grammar. London: Macmillan Heinemann.

[21] Van Lier, L. (2000). From input to affordance: Social-interactive learning from an ecological perspective. In J. P. Lantolf (Ed.), Sociocultural theory and second language learning: recent advances. Oxford: Oxford University Press.

[22] Van Lier, L. (2004). The ecology and semiotics of language learning: A sociocultural perspective. New York: Kluwer Academic Publishers.

[23] Waldrop, M, M. (1992). Complexity: The emerging science at the edge of order and chaos. Simon and Schuster. New York.

[24] Zellermayer, M. \& Margolin, I. (2005). Teacher educators' professional learning described through the lens of complexity theory. Teachers College Record, 107, 1275-1304.

Mohammad Hashamdar received his MA in TEFL in 2001 and became a faculty member of Islamic Azad University, Karaj Branch. He is currently doing his PhD in TEFL at Islamic Azad University, Science and Research Branch. He has been teaching English at different levels for 19 years and has published two books and some papers in international journals. His research interests are critical thinking, first language acquisition, and second language acquisition. 